\title{
BUILT ENVIRONMENT FRACTALITY AS A CRITERION OF SPACE MANAGEMENT
}

\author{
Maja Jevrić* \\ Faculty of Civil Engineering, Podgorica, Montenegro \\ Dr Branislav Popkonstantinović \\ Faculty of Mechanical Engineering, Belgrade, Serbia
}

In accordance with the holographic paradigm of the universe, recent studies indicate the importance of fractality of the human environment for his mental and physical well-being. There was awareness of that in the past, but the conventional methods of planning cities have forgotten that. The lack of hierarchy and human scale in modern cities, as so as its geometrically regular shapes and flattened lines, are associated with some negative social phenomena. Therefore, this paper aims to highlight the importance of fractality of built environment and to suggest the possibilities of its use as a criterion of space management.

Key words: Fractals, Complexity, Space management, Decision making, Fractal dimension

\section{INTRODUCTION}

Parallel with revealing of fractal theory, complexity theory and chaos theory in the mid of $X X$ century, and with the rapid advancement of technology which has enabled further development of these theories, their frequent connecting with other scientific disciplines is evident. Introducing the chaos theory into urban planning requires a comprehensive change of the concept - requires awareness that there is not just one but a number of possible scenarios for the future development and that it involves a number of deciding factors, as well as a large number of objectives.

Conventional methods of space management and planning have not shown as adequate to meet all the rapid changes in town, related to population size, lifestyle and technical-technological development of infrastructure systems. For such a changable and complex system such as city, the traditional methods of analysis were insufficient because they did not treat the nonlinearity of the problem and a large number of system parameters... Knowing that the management processes are interconnected with their results, i.e. result of one process becomes the input for another [01], the similarity with the process of generating fractals is obvious.

So far the cities have not been generally treated as complex systems. Planners, settlement builders and decision makers treated them as simple predictive systems that needed to be arranged and reduced to their components for easier urban modelling and urban problem solving. The conventional planning methods, based on the application of Euclidean geometry, have shown many disadvantages. [02]

The city is characterized by the complex organization as a result of the interactions between its elements. It is an open system and its form and function continually change and affect the environment, as the environment affects them. Therefore, cities are perceived, more than any other human creation, as self-organized living systems, which can not be described by conventional linear and mechanical principles. Nikos Salingaros claims that degree of vitality of city depends on its possibility to achieve its own natural complexity. [03]

Previous researches have shown that urban patterns have fractal structure. [02-08] The effects of the modern era, such as increasing car traffic, adversely affect the hierarchical principles typical for such structures, i.e. agglomerations become more uniformly shaped. The loss of physical complexity of built environment, as well as the lack of structures in human scale [09], adversely affects the human mind [02], what can be related to many negative trends (e.g. sense of alienation, occurrence of violence...). In this regard, the studies [02], [09] have given emphasis to the necessity of relationships and structures at all 
scales of urban pattern, from the agglomeration level to the neighbourhood level and beyond - to the architectural details. Fractal principle can be recognized in this.

Fractal geometry as a "geometry of organized complexity" is suitable for the description of complex systems such as cities. Since "fractal is a resulting image of the chaotic behavior of the system within a complex system", the properties of fractals can be applied to the analysis of the forms of the city. [10]-[12] Measurements of fractal dimension of urban areas and urban boundaries, can provide important input for planning of future development of the city. However, in this paper, we point out the possibility that fractality of built environment become one of the criteria of decision making in space management. Fractality, as a desirable feature of urban form, however, may also be one of the objectives of the built environment management.

\section{GOALS, OBJECTIVES AND CRITERIA OF MANAGEMENT}

Effective management assumes a clear understanding and definition of the different objectives: basic and operational; short-term and long-term.

Management involves choosing the best or the satisfactory control action from a set of the available ones. To make choosing possible, it is necessary to predefine criteria for comparison of control actions, so-called management criteria. On the basis of these criteria, selection, ranking of available control actions and selecting the best one can be done. Accordingly, it is very important to choose the criterion that leads to the goal on the best way.

The definition of criteria for specific control actions is generally a very difficult problem, especially when it comes to complex systems such as cities. In that case, many requests, often conflicting ones, which can not be captured by a single criterion, should be taken into account. [13] Then, so-called multicriteria decision making should be done, taking into account several criteria in solving management problems.

The problem becomes more complex if the description criteria are considered, such as the quality of life in an urban environment, spirit of the place, feeling of satisfaction in a pleasant environment, safety, etc. which are very difficult to quantify. Some studies [02, 03] speak in favour of the observation that these qualities are associated with the complexity of built environment. So far it has not been possible to quantify these criteria, but analysis have show that fractal dimension has got potential for it, in combination with some other parameters (e.g. lacunarity). However, the further investigations are necessary.

\section{ABOUT FRACTALS}

The term fractal describes the objects which are not geometrically regular at first sight. Euclidean geometry describes them as shapeless or amorphous but there is a certain order (pattern) found in their structure. „Fractal is irregular or fragmented geometrical shape that can be divided into parts, whereas each of them is, at least aproximately, copy of the whole." [14] They mostly occur in nature, e.g. in the microstructure of DNA, crystals, plants, certain organs in humans, clouds, mountains, lightning, coasts, galaxy, in heartbeat fluctuations, weather forecast, earthquakes...
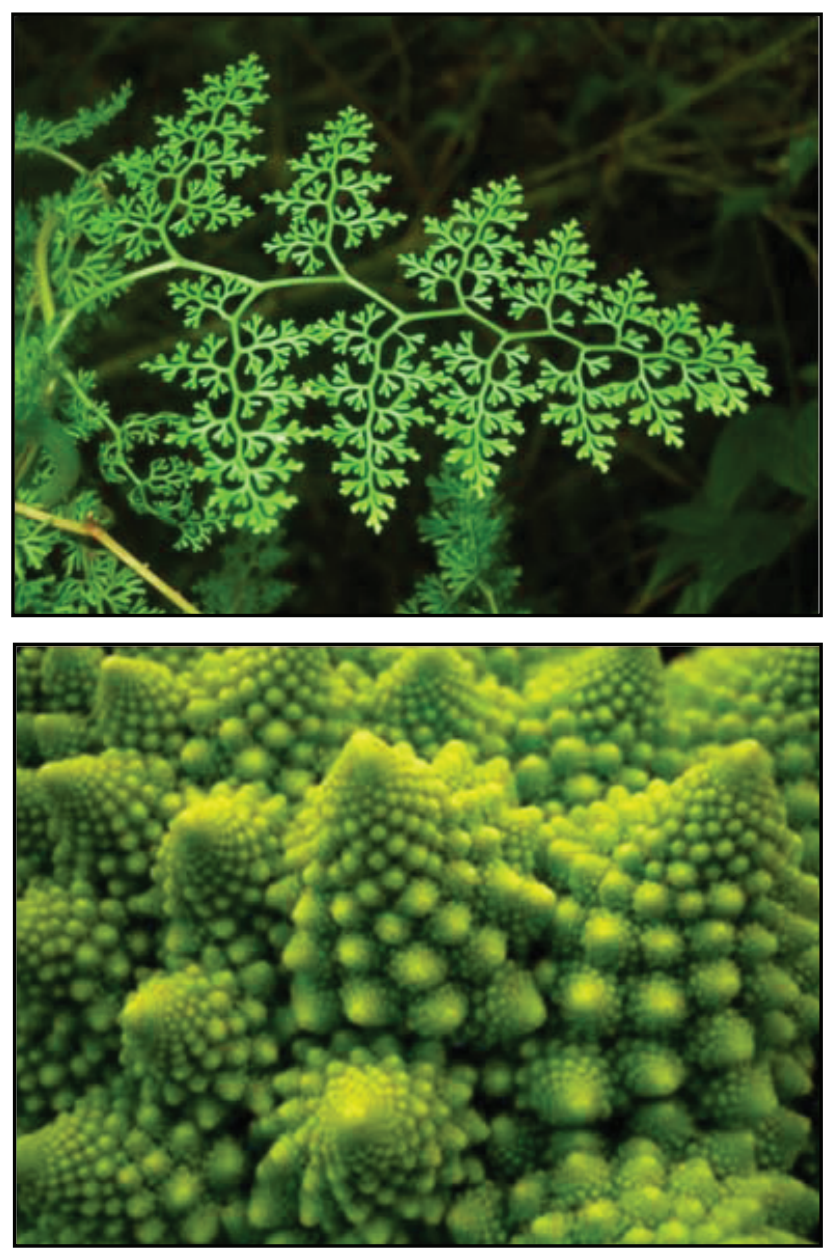

Figure 1: Examples of natural fractals 
However, as the "father of fractals", Mandelbrot says that clouds are not spheres, mountains are not cones, coastlines are not circles, and bark is not smooth. Thus, neither Euclidean geometry, with its regular geometric shapes and integer dimensions, can describe in the most appropriate way the forms found in nature [14]. Therefore, fractal dimension (Df) is introduced to "measure" how well a structure fills the certain space. The street network in the city tends to reach every part of the city and each facility, so its fractality is unquestionable.
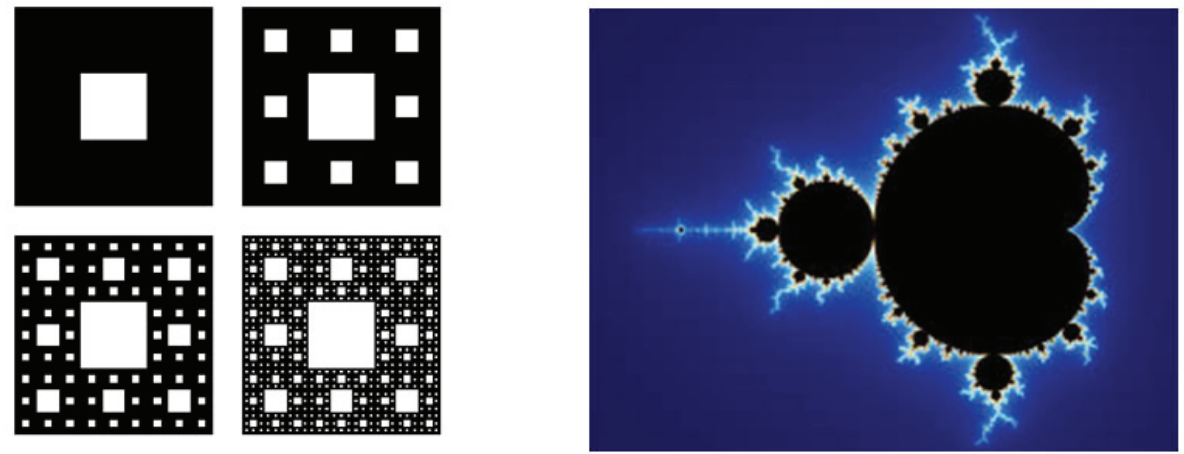

Figure 2: IFS and mathematical fractals

Fractals have the ability to summarize complexity, density and heterogeneity of space distribution in a single value - fractal dimension, which is independent of the scale. [03-05]

The fractal dimension of the built environment describes the distribution of structures in the plane of observation (ground plane or elevation) and can have values between 0 and 2 . If $\mathrm{Df}=2$, it means that the urban pattern is uniform, while 0 corresponds to marginal case where the pattern is made of one point i.e. an isolated object. [08]

There are many methods for fractal dimension estimation. Most of them can be appropriate for the urban pattern analysis. All methods are based on the same principle of logarithmic equation and tend to define a relationship between the object size and different scales of fractal dimension estimation.

If the subject of the analysis is the image of the inhabited area (its ground plan), the calculation of its fractal dimension is based on the separation of the occupied from the free pixels (the inhabited from the uninhabited areas) according to binary logic - assigning one colour to occupied pixels and other colour to free pixels. For the estimation of fractal dimension of built settlement in practice, ortophoto is used, prepared and processed as particular computer tool for fractal analysis (Benoit 1.3, Fractalyse, FracLac, Fractop...) demands.

\section{FRACTALITY OF URBAN PATTERN AS A CRITERION OF SPACE MANAGEMENT}

Fractal structures are occured in many natural sistems. If the fractal principle is the principle by which nature is organized [14], then human beings are expected to perceive their environment in the same manner. Accordingly, human brain is fractal, too. People react to the level of complexity of what they see. [11] Fractality is an inherent property of human environment because of human beings have been surrounded by fractals for millions of years, so, large part of the structure of human mind comes from this ancient relation. The environment, i.e. what human eyes can see, influences humans, thus the human mind is fractal. Only recently humans are surrounded by structures that are not fractal [02].
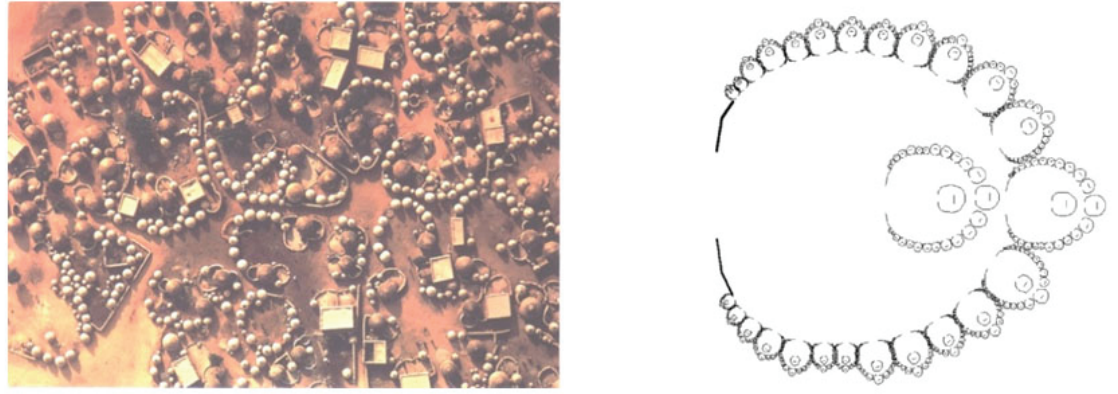

Figure 3: Aerial photo and scheme of African settlement (from [15]) 
In contrast to fractal natural structures, only in rare examples of built structures, mostly in traditional architecture, fractality occurs. Traditional builders had a knowledge about fractal concept (in examples showed in Fig.3) when they considered shape of settlements, as well as about respecting of human scale. In the modern cities design, the fractal concept is forgotten. The cities characterized by straight lines of Euclidean geometry are planned for cars, more than for humans, so people lose their natural connection with the environment. How fractality of built environment could be used as a criterion for decision making in space management?

Fractal classification, i.e. zoning according to the value of fractal dimension, can help planners to identify more precisely the boundaries of the zones where some interventions can be implemented to maintain complexity of the urban area. [11] If two neighbouring zones have different fractal dimensions, it can be a sign for paying attention to that area, in order to get a more uniform complexity.

The determination of fractal dimension enables the estimation of the changes in physical complexity caused by particular project demands or interventions, which have a direct morphological influence on urban patterns, by comparing fractal dimension estimated before and after the "marked" change. [11] Based on this, it is possible to gain insight into the obtained level of integration of the considered new building with the existing urban space. For example, a big intervention in space often has negative influence on the area complexity, what can be detected through fractal dimension decreasing.

Fractal dimension of urban boundary indicates fragmentation/compactness (related to the urban sprawl issue) of the urban patterns. The information about $D_{f}$ of the urban boundaries and $D_{f}$ of the urban area can be used as a parameter for decision-making about spatial development. For example, when planning new residential areas, additional free areas are often used for further spatial development, which is not in accordance with the principles of rational space use.

Fractality of infrastructure networks can also be considered as a criterion of decision making. Since the fractal dimension of line "measures" how well the curve fills the certain space, fractality of traffic networks is a good indicator of its branching, i.e. the way the area is covered by roads.
Another possible form of the application of fractals is related to tax policy. Developing methods of application of fractals to assess the quality of urban entities or location would lead to providing criteria for the tax amount determination, or policy of stimulating (or destimulating) to the use of a particular area.

\section{CONCLUSION}

Human natural environment (relief, galaxies, flora and fauna, natural phenomena...) is fractal. Since human beings have been surrounded by this fractal structures for the millions of years, it is not surprising that people lose this important relationship with their environment in their modern, „anti-fractal“, cities. However, the importance of built environment fractality for human mental and physical well-being continue to be examined and proven. Although additional research on this issue is needed, in this paper we have tried to point out the reasons and the possibilities of using fractality as a criteria in decision making proces of space management.

Fractal dimension of an urban pattern shows how the area is filled by built structures. By changing fractal dimension of the area, the change of complexity and heterogeneity of the built environment can be achieved. Varying the fractal dimension of urban boundaries can affect the prevention of the urban sprawl emergence and an irrational space consumption consequently. Further research is needed in terms of combining the values of fractal dimension with the coefficient of land use or with some another urban parameters.

Fractality of built environment (ground plan of urban pattern) is considered in only one (the first) projection here. That can be a useful tool in planning process but further research should include analysis of the street elevation, appearance of the facade, city outline, street vistas...

\section{REFERENCES}

1) Batty, M. \& Longley, M.: ,Fractal Cities”, Academic Press Limited, San Diego, CA and London, 1994.

2) Batty, M.: „Cities as Complex Systems: Scaling, Interactions, Networks, Dynamics and Urban Morphologies", www.casa.ucl.ac.uk, 20.10.2012.

3) Batty, M.: ,The Size, Scale, and Shape of Cities”, Science, 319 (5864), pp.769-771, 2008. 
4) Cooper, J. \& Oskrochi, R.: ,,Fractal analysis of street vistas: a potential tool for assessing levels of visual variety in everyday street scenes", Environment and Planning B: Planning and Design, 01/2008, pp.349-363, 2008.

5) Eglash, R., Diatta, C.S. \& Badiane, N.: ,,Fractal structure in Jola material culture", Ekistics 61, pp. 367-371, 1994.

6) Frankhauser, P. \& Thomas, I.: ,,The morphology of built-up landscapes in Wallonia: a classification using fractal indices", www. math.univ-lille1.fr, 10.03.2013.

7) Frankhauser, P.: ,Approaching urban patterns by fractal geometry : From theory to application", http://cddthema.univ-fcomte.fr ,15. 04. 2013.

8) Haghani, T.: ,,Fractal Geometry, Complexity and the Nature of Urban Morphological Evolution", www. fractalmorphology.com, 20.08.2011.

9) Jevrić M.: „Pristup proučavanju forme grada primjenom teorije kompleksnosti", International Conference GNP, Proceedings,
Žabljak, 2012.

10) Jevrić, M. \& Kalezić, J.: „,Fractals in urban space", Internacional Conference of Geometry and Graphics, Proceedings, Belgrade, pp. 186-195, 2010.

11) Jovanović, P.: ,Upravljanje investicijama”, Fakultet organizacionih nauka, Beograd, 2006.

12) Knežević, M.: „Upravljanje rizikom pri realizaciji građevinskih projekata", phD disertation, Građevinski fakultet, Beograd, 2005.

13) Mandelbrot, B.: ,,The Fractal Geometry of Nature", W. H. Freeman and Company, New York, 1983.

14) Radović, R.: „,Forma grada”, Osnove teorija i praksa, Orion Art-Stylos, Bg-Novi Sad, 2004.

15) Salingaros, N.: ,Ecology and the Fractal Mind in the New Architecture", www.fractal. org, 20.04.2013.

Paper sent to revision: 07.02.2014.

Paper ready for publication: 15.03.2014. 